\title{
Kathleen Heugh and Tove Skutnabb-Kangas. Multilingual Education Works. From the Periphery to the Centre. Orient-Biackswan, Hyderabad. 2010.376 pp.
}

\author{
Peter Plüddemann \\ University of the Western Cape
}

ppluddemann@uwc.ac.za

\begin{abstract}
In this review of Multilingual Education Works I will be providing an overview of the book before providing chapter summaries that focus on recurring themes. A concluding section offers some suggestions on how an already compelling volume could be enhanced.
\end{abstract}

\section{INTRODUCTION}

Tn international debates on educa1 tion's contribution to overcoming poverty and the marginalisation of social minorities, the issue of the medium of instruction (Mol) has featured strongly ever since UNESCO's endorsement of vernacular (mother-tongue) education in 1953. Almost six decades later, the major research evidence for the desirability of mother-tongue based multilingual education (MLE) for social and political minorities has come mainly from the USA, and from Nigeria's famous but isolated six-year Yoruba mother-tongue project in the 1970s. Despite a host of subsequent resolutions by African governments, regional bodies, and pan-African organisations, all of which have recognised the centrality of the mother tongue in educational performance, cultural identity and national development, Africa in particular (and the political South in general) has had very little to show - until now.

The present volume begins to fill the gap. In the words of editors Kathleen Heugh and Tove SkutnabbKangas, Multilingual Education Works aims to contribute to the beginnings of a South-South dialogue in the field of multilingual education, and 'to demonstrate that in low-income contexts where educational practices are inclusive of 
linguistic diversity and responsive to local conditions and community participation, recent compelling data show successful implementation of bilingual and multilingual education even within limited budgetary investment' (6). This purpose is served by this timely and self-aware volume, which follows the path of the direction-giving report on mother tongue and bilingual education in sub-Saharan African (Alidou et al. 2006). The present volume has as its hub Ethiopia's commitment to MLE since 1994. Following a general introduction, successive chapters by a strong cast of authors present a range of country/ region case studies that are compared and contrasted with Ethiopia in dialogic fashion. These include studies from West and North Africa (Burkina Faso, Morocco), South Asia (India, Nepal), mainland Southeast Asia (Thailand, Vietnam, Laos, Cambodia), South America (Peru), and North America (USA). The book returns to Ethiopia for a detailed analysis of systemic assessment results measured against the various models of MLE, and concludes by summing up key themes and consolidating insights into how MLE can be made to work. The volume is enhanced by a sensitively-worded preface by Adama Ouane that locates MLE within the ambit of cultural diversity and takes the measure of the editors' agency, and a poignant poem by Dainess Maganda. The result is a persuasive product that provides long-awaited answers to the language education question in the political South. In so doing, the book does indeed contribute to shifting the political South from the periphery to centre-stage.

As suggested by the pun on 'works' in the title, this edited volume has the unmistakable feel of a manifesto. The message is clear. As the editors remind us in their introductory chapter, the education system as currently constituted is failing hundreds of millions of indigenous, tribal and minority (ITM) children, particularly in Asia, Africa, Latin America, and the Pacific. This has much to do with the languages that are used for teaching and learning at primary school level. In brief, the world's ITM children suffer under the lack of fit between the language (and culture) of the home or community, and that of the school. In the process social minorities are denied the use of their most fundamental resource, their mother tongue, which amounts to a denial of human rights that deeply affects the realisation of their capabilities. The chapters in this book present an alternative to a system that is both profoundly unjust and financially wasteful. Collectively, they provide new evidence of the universal applicability of the 'mother-tongue first' principle and the feasibility of MLE, always under specified conditions.

Throughout, Kathleen Heugh's and Tove Skutnabb-Kangas' voices, as well as coauthor Carol Benson's, come through in their appraisal of MLE. Liberal use is made of positive polarity ('there is, quite simply, no other choice than to proceed with strong, additive bilingual and multilingual options' (19), positive appreciation (of MLE), negative appreciation (of the washback effects of the quest for English in Ethiopia), positive judgment (of those struggling for MLE against difficult odds), negative judgment (of ill-informed foreign language experts who dispense advice without staying long enough to get a sense of local dynamics), and amplification and attitudinal lexis ("...the most dire consequence [of failed measures to upgrade learners' and teachers' English proficiency] has been to convince everyone 
that English is more important than learning.' (75)). Use is also made of interpersonal resources such as modal adjuncts (Aspiration towards English proficiency is unfortunately equated with adopting English medium education ....' (74)). The combined effect leaves the reader in no doubt as to the contributors' valorisation of MLE, and their desire to persuade readers. All three are lifelong activist-intellectuals, and the result is a persuasive and at times exhilarating book.

\section{CHAPTER SUMMARIES}

Several themes course through the chapters of this book. The most prominent of these are the question of political will in relation to policy implementation; the confirmation of international bilingual education theory; the locus of decision-making in regard to language education matters; the 'value-added' dimension of culture and community participation in the curriculum; the question of script choice for newly-codified languages; and the threat of washback. The relevant themes will be highlighted in the chapter summaries that follow.

Political will, decentralisation and washback emerge as strong themes in the case studies from Africa. The cornerstone of this book is made up of the contributions about Ethiopia. In their two chapters on Mol in Ethiopian primary schools, Carol Benson, Kathleen Heugh, Berhanu Bogale and Mekonnen Alemu Gebre Yohannes show why the country's language-in-education policy can be regarded as exemplary: it is research-aligned; implementation is effected through decentralisation; and national assessments of student achievement provide an empirical basis for comparison across the nine regions and two city states. Excitingly for the advocates of MLE worldwide, the results confirm decades of bilingual education theory and research. The best performing regions are those that have realised the policy objective of MTM throughout the 8 years of primary schooling, and for both cycles of teacher training. Next best are those regions with 6 years of MTM, then those with 4 years of MTM, and lastly those with no MTM but with 6 years of Amharic L2 medium. The authors acknowledge that absolute scores for key subjects are so low as to raise serious questions about the education system, and the high school prospects of the nation's youth. I shall return to this point in my concluding comments. The significance of Ethiopia's commitment to MLE lies in the comparability of the various late-exit, early-exit and L2 immersion models via the regular, countrywide systemic assessment data. In combination, the two chapters show that the results confirm 'decades of language acquisition, bilingual and multilingual theory', and that they parallel results from bilingual education research in the USA. The authors identify as the main threats to MLE the washback effect of English, bemoaning the lost potential of Amharic as a countrywide L2, the role of multinational textbook publishers who have their own agendas, and the fact that MT teacher education has recently been undermined by Englishcentred teacher education requirements. In similar vein, a third chapter on Ethiopia, by Jeylan Wolyie Hussein, shows the ambivalence towards English amongst Ethiopian university students, for whom the language is both prized and feared. The chapter presents the findings of a survey of Ethiopian university students' views on English, the 
language of tuition. As a result of their lack of proficiency in academic English, students experience insecurity and low self-esteem, and spend disproportionate amounts of their time on mastering academic English at the expense of course content.

The confirmation of bilingual education theory continues with the study of Burkina Faso's multilingual education model, by Paul Taryam llboudo and Norbert Nikièma. For several decades after independence, post-colonial educational policies and the country's internal upheavals delayed official recognition of bilingual education as an option in primary education. In an effort to overcome the debilitating diglossia (French vs local languages) as manifest in the split between formal schooling and non-formal education/ adult literacy, the government allowed but did not initiate multilingual education models from the mid-1990s. The authors discuss the most promising of these, which provide for an extension of early-exit bilingual programmes to five years of MTM education in eight national languages with the transition to French as Mol in Years 3 and 4 of primary schooling. Teacher training includes a bilingual component. The programmes, which began with outof-school youth, have been internally efficient in relation to classical (Frenchmedium) schools. Among the lessons learnt from the programme are that African MTs can be an effective learning tool; that bilingual schooling enhances parental participation; and that MLE is cost-effective in relation to monolingual education in a foreign language. Challenges identified by the authors involve the need for advocacy to counter public negativity around linguistic diversity; developing a more integrated pedagogy of MTs and French; moving beyond a single measure of bilingual education's success (i.e. proficiency in French in the school-leaving exam); and, for the government, to show its seriousness by meeting growing public demand for MLE.

By contrast, the overlapping themes of political will and centralised decision-making with regard to language policy and planning characterise the situation in Morocco. Here, as author Ahmed Kabel shows, medium of instruction policies are tightly controlled from the centre, and are highly charged politically. After outlining the complex sociolinguistic situation involving three main varieties of Arabic, as well as Amazigh (Berber) and French, the author discusses Amazigh language in education against the politics of state formation in the post-independence era. Kabel exposes Arabisation, supposedly a tool for nation-building, as an instrument of elite closure - keeping the Arabic-speaking masses at bay - and of political exclusion of the Berber people. The breakthrough for Amazigh language in education came in $1994 / 2001 / 2004$, with the first Berberas-a-subject classes. From the start, the choice of script of this previously oralonly language was politically fraught. The decision to standardise a macro variety of Amazigh effectively resulted in de-dialectalisation / purification, something likely to alienate young learners and result in social class stratification. The author problematises the key criterion of 'authenticity', which sought to artificially undo centuries of language contact between Berber and Arabic, and concludes by identifying problems of implementation, such as centralised decision-making, the lack of training for teachers and trainers of Berber, and persistent negative attitudes towards the language. 
Not unlike the Moroccan example, the chapter on language-in-education policy and practice in Southeast Asia, by Carol Benson and Kimma Kosonen, introduces readers to a socially stratified set of societies. Cambodia, Laos, Vietnam and Thailand that continue to marginalise so-called ethnolinguistic minorities and the non-dominant languages (NDL) they speak. Some 'paper policies' exist for NDLs; however, these are often not implemented. A complicating factor is the choice of script, a decision that is frequently taken in a top-down manner and is inevitably politicised. The authors suggest that for new languages, the scripts of neighbouring languages be used. Government thinking on bilingual education tends to be limited to the national language plus English, and is seldom extended to minority languages. As a result, speakers of NDLs do poorly on the whole. The four countries differ in respect of the degree of decentralisation of decision-making. The authors point out the dangers of decentralisation for MLE, and argue for a stronger degree of centralised decision-making (as in Vietnam and Laos) in cases where regions do not have the requisite understanding or resources. On the other hand, if the political will is lacking, a centralised system could paralyse all efforts at promoting NDLs. Interestingly, the authors suggest that one way of dealing with linguistic heterogeneity is to develop NDLs for use in non-formal education (as in Papua New-Guinea) before introducing them into formal schooling. Local communities have an important role to play in this regard.

Ajit Mohanty's chapter on South Asian countries (with special reference to India) shows the 'double divide' between the international language of wider communication and major national languages, on the one hand, and between the latter and the indigenous and tribal minority (ITM) languages, on the other. In the Indian context this translates into the power gap between English and the national language Hindi, and between Hindi and regional ITM languages, a gap that is reflected in educational language policy and practice. The chapter highlights the shortcomings of India's ThreeLanguage Formula, adopted after independence, and of recent legislation that similarly does not guarantee education in the MT. Despite popular demand for English in India, in practice an English mainly approach is shown to be unworkable: (so-called) tribal children are being taught English in Hindi, there is no home support for English, teachers are not competent to teach in English, and classroom teaching of English is marginal in some tribal areas. Mohanty argues instead for a lateexit multilingual approach. In the absence of state provision, experimental MLE programmes have had to be set up, supported and evaluated by a National Multilingual Education Resource consortium. These MLE initiatives for tribal minority children for the first 3-5 years of schooling gradually phase in the state majority language as a Molalongside the MT as Mol, eventually replacing it while the $\mathrm{MT} / \mathrm{Ll}$ continues as subject. Indigenous cultural knowledge systems provide added value in MLE + programmes, which otherwise follow the state school curriculum. Encouragingly, MLE and MLE + programmes have shown positive results. However, negotiating the double divide remains a big challenge.

The South Asian country of Nepal is accorded two complementary chapters on its nascent MLE policy and 
implementation. The first, co-authored by llina Nurmal, Lava Deo Awasthi and Tove Skutnabb-Kangas, outlines the historical, sociolinguistic and international as well as local policy contexts and processes around MLE in this diverse country still recovering from civil war. Nepal is an economically poor country recovering from the valorisation of Nepalese as the national language at the expense of ITMs, which were rendered invisible. There have been recent policy gains for ITM languages, although implementation has been slow. The pilot Multilingual Education Programme of 2006-2009, for non-Nepali speaking learners, uses eight languages. The programme inception phase identified as a challenge the fact that MLE was a new concept in Nepal as a challenge, as well as a whole range of advocacy, training and resource needs. It also recommended that Nepali should be developed as L2, and that the strong oral tradition in Nepal be valorised and used to develop literacy. Above all, the programme needs to expand into a nationwide strategy for MLE with flexible models in which local content and indigenous cultural and knowledge feature prominently. Encouragingly, MLE has brought about a shift of focus from teaching (and rote memorisation) to learning. Shelley Taylor's chapter on implementation issues stresses the need for conceptual clarity around MLE (Ll-based programmes; culturally relevant pedagogy), and for ironing out 'glitches' in teacher training. It provides nuance by distinguishing between monolingual and multilingual MLE, and identifies six different types of classroom organisation. In a richly descriptive account, Taylor shows how a 'funds of knowledge' approach was followed to ensure that teacher training and materials development were conducted in a culturally sensitive, empowering manner. Challenges identified include the need to move beyond 'consecutive interpretation' to MLE, and to access resources for implementation. Taylor ends by highlighting the importance of a pro-active approach: 'Glitches can be fixed, but opportunities lost often do not arise again' (218).

The two chapters on the Americas highlight culture and community involvement issues and the need for different multilingual education models. In her chapter on Native American language education, Teresa McCarty challenges the either-or paradigm which makes a decimated indigenous minority people feel compelled to choose between MTE and schooling in the language of wider communication (English). McCarty reports on two different models of bilingual-bicultural education involving the Navajo community in Arizona. The first, 'mother tongue as first language', discusses three examples of scaffolded dual-medium schooling built on MT foundations, with substantial local knowledge and cultural values reflected in the curriculum. The second, 'mother tongue as second language', amounts to a language and culture revitalisation project in which minority children with only receptive capacity in their heritage language are either successfully immersed in the language as sole MT throughout school, or exposed to a 90-10 dual-medium programme that ends with 50/50 curriculum time allocation by grade 6 . Both types of projects have produced impressive results across the curriculum, restoration of cultural pride, and high parent involvement. In sum, they see successful programmes as those that are highly context-specific, integrate indigenous culture into learning of the heritage MT and academic content, 
involve the whole school, are culturally based, and develop indigenous teacher education programmes and curricula that match the desired outcomes of schooling.

The question of cultural identity occupies a similar prominence in indigenous people's struggles for MLE further south in the Americas. In their chapter on language and education in Peru, Susanne Perez Jacobsen and Lucy Trapnell Forero highlight the close links between education, language, culture and power, a mix that has resulted in the concept and practice of intercultural bilingual education (IBE). In practice, despite an enabling policy framework, IBE for Peru's indigenous peoples is not implemented: the state has appropriated intercultural discourse, but diluted its liberatory potential. In the absence of the state's political will to train teachers in IBE, for example, implementation is ad hoc and is left up to individual teachers. As a result, old myths about the supposed 'unsuitedness' of local languages to teaching mathematics and science are not systematically addressed. In most IBE schools Spanish is learnt through immersion; NGOs are pushing for the teaching of Spanish as an L2. A policy of decentralisation does exist, and there are alternative curricula that promote indigenous knowledge as social and cultural construction. However, most curricula do not give enough importance to the community base. The authors conclude that unlike in Ethiopia, the mobilisation of indigenous people is vital to IBE in Peru. Large-scale assessment studies (as in Ethiopia) are needed to provide proof of the success of IBE and to challenge existing beliefs and misperceptions. Importantly, IBE curricula need to go beyond translation from the Spanish and consider intercultural aspects as well.
The book's concluding chapter brings together the mainthemes of the book. In the words of authors Kathleen Heugh and Tove Skutnabb-Kangas, the various case studies affirm that '[m] ultilingual education works when 'peripheries' take centre stage'. As a result the symbolic (or political) South has much to teach the 'late-developers' of western Education. MLE helps learners negotiate the curriculum better, enhances self-esteem, improves retention rates, and involves parents and communities. It is the writing down of local languages, i.e. their production in print, that fundamentally enhances their status and impacts on power relations between languages in a given linguistic ecology. The overall goal should be to move beyond universal primary enrolment to increasing enrolment in secondary education. In this regard research findings have an important role to play in guiding governments. The authors reserve some of their strongest criticisms for the ethics of intervention and research, and for the dubious role some external language consultants play. Given the weight of evidence, the authors aver, opposition to MLE is fundamentally ideological, and has little to do with research findings. They note with concern the pressure towards the dominant or majority language especially English in many societies of the South, as indexed by reverse planning and the washback effect of high-stakes assessment or gatekeeping. This notwithstanding, it is fitting to join the authors in affirming that MLE works where a judicious mix of strong government support and enabling decentralisation exists, where governments implement their promises, ensure that teacher development occurs through local languages and that teachers are placed in communities 
where they and the learners share a common language.

\section{Points to consider for future editions}

Multilingual Education Works goes a long way to establishing the viability of MLE in linguistically diverse settings. The authors, in particular the editors, have done the international activist research community a favour with their rigorous contributions. It should no longer be necessary for ministries of education in the political South to ask, with reference to the validity of MLE, 'But where is the evidence?' However, as with all books of this nature, there are always points on which even those who share its broad paradigm will differ with the contributors. Any future editions of this volume would, in my view, be enhanced if the three points outlined below were given considered attention.

The first issue concerns the limits of research into matters of language in education, and the risk of overstating the importance of the language-medium issue. The book's central claim is that for the majority of the world's marginalised people (ITMs), MLE is more effective and more desirable than its opposite, namely education based on an unfamiliar or less well-known language. But in contexts of poverty, to what extent is it really possible to isolate language as the decisive factor in the teaching-learning equation, and then to predict performance on the basis of the degree of fit between learner MT and the Mol? At times the authors of the Ethiopian study, in particular, imply that it is possible to do so, and appear to posit a 1:1 relationship between degree of fit and students' academic achievement. At other times, other mitigating factors are invoked, notably political instability in some regions, remote rurality, nomadic lifestyles, and variable capacity in district offices. It is not always clear why such caveats should not extend to other factors such as the political exclusion of some minority groups, codification and the choice of script, and the availability of literature and environmental print in NDLs (see also Stroud 2002). All this is not merely to reiterate that maximal exposure to MTM at primary school is a necessary, as opposed to a sufficient, condition for success. It also makes the point that in some contexts, the Mol may not even be the decisive factor in school performance. If we take the scores from the Ethiopian study, for example, what is more striking than the differences in achievement between the top groups (MTM8 - e.g. Tigray's $42 \%$ average in 2008) and the bottom groups (MTMO, i.e. L2 Amharic throughout - see Benishangul Gumuz's 32\%) is the poor performance across the board. The difference in scores is significant, and can probably be safely attributed to a small cluster of factors of which language may well be the most salient. But if even the MTM8 groups come nowhere close to averaging $50 \%$ for the specified subjects, there is a far bigger problem that has nothing to do with Mol. This insight, taken to its logical conclusion, suggests the need for a broader research focus that includes issues of resourcing, class size (teacher: student ratio), teaching methods, teachers' conceptual knowledge, and the validity of the tests used. It might even include an ethnographic study of the children's existing 'funds of knowledge', and the extent to which these are (not) represented in the curriculum.

Secondly, there is the bothersome matter of definitions. Commendably, 
in a field riddled with language ideological disputes, the editors take care to define their terms whilst acknowledging the philosophical debates and differences surrounding these. The central concept of MLE is purposively described in terms that make it amenable to practical application:

MLE, mother-tongue-based multilingual education, is based on strong development of the mother tongue (or language of the immediate community best known by the child), with the addition of at least one other language (often two or even three other languages). All will be used for teaching some subjects, in a carefully considered sequence, to achieve high levels of multilingualism and multiliteracy. Bilingual education is a subcategory under multilingual education. (p.xii)

The definition sits uneasily between a means (or forms) definition of bi-multilingual education, which takes its name from the number of Mol used (2 Mol = bilingual education, 3 Mol = multilingual education), and an ends definition, which emphasises the goal (e.g. high levels of multilingualism) without specifying the number of Mol (cf Cummins 2003). The problem with the above definition of MLE is that it tries to have it both ways. On the one hand, it begins by stating that only forms of schooling in which all the languages that are 'added' to the MT are used as Mol qualify as MLE. Clearly, therefore, the use as Mol of only one of the two 'added' languages does not constitute MLE. By the same token, Ethiopia's three strongest regions (Tigray, Oromiya, Somali) - those which offer MTM8 before the switch to English as Mol and where Amharic is learnt solely as a subject - do not qualify as MLE. On the other hand, the definition adds (as if realising the seriousness of the omission) that bilingual education is a subset of multilingual education. Assuming 'bilingual education' to involve the use of two Mol and to include models in which a third language is learnt solely as a subject, this formulation allows models in which only one of the two 'added' languages is used as a Mol to be reinstated as MLE- through the back door, as it were. One way to get around the resultant contradiction would be to change the wording in the second sentence from 'all will be used for teaching some subjects' to 'at least two languages will be used as Mol...' In that case the reference to 'bilingual education' becomes redundant. An alternative strategy would be to adopt the goals definition. Either way, the definition as it stands ought to be refined.

Finally, and paradoxically, one of the book's great strengths is also a potential weakness. The fact that the Ethiopian case study is a reference point for all the other chapters gives the book a unity of purpose and content that is rare in edited volumes of this kind. All the authors make detailed references to the lessons learnt from Ethiopia's commitment to MLE, such as the decentralisation of decision-making, and the Mol alignment of teacher education with schooling. Several authors also show how Ethiopia stands to learn from contexts that emphasise intercultural bilingual education and community participation, for example. The resultant comparison-contrast offers a rich array of insights from which all parties stand to benefit. Inevitably, however, this results in repetition perhaps too much of it, in the present instance. In the later chapters I found myself skipping over the bits in which a comparison with Ethiopia was being 
made yet again. This is, however, easily remedied by a scrupulous edit. That there should be revised and updated editions of this excellent volume for many years to come is, in my view, beyond question.

\section{REFERENCES}

Alidou, H., Boly, A., Brock-Utne, B., Diallo, Y S., Heugh, K. and Wolff, H.E. 2006.
Optimizing Learning and Education in Africa - the Language Factor. A Stocktaking Research on Mother Tongue and Bilingual Education in Sub-Saharan Africa. ADEA, UNESCO \& GTZ.

Cummins, J. 2003. Bilingual education. In J. Bourne and E. Reid (eds.), Language Education. World Yearbook 2003. London \& Sterling (USA): Kogan Page, pp. 3-19.

Stroud, C. 2002. Towards a Policy of Bilingual Education in Developing Countries. New Education Division Documents No. 10. Stockholm: SIDA. 